\title{
Lupin protein influences the expression of hepatic genes involved in fatty acid synthesis and triacylglycerol hydrolysis of adult rats
}

\author{
Anja Bettzieche, Corinna Brandsch, Kristin Weiße, Frank Hirche, Klaus Eder and Gabriele I. Stangl* \\ Institute of Agricultural and Nutritional Sciences, Martin-Luther-University Halle-Wittenberg, Emil-Abderhalden-Strasse 26, \\ D-06108 Halle (Saale), Germany
}

(Received 14 May 2007 - Revised 18 September 2007 - Accepted 20 September 2007 - First published online 21 December 2007)

To assess the effect of lupin protein on concentrations of lipids in plasma lipoproteins and liver and hepatic mRNA concentrations of genes involved in lipid metabolism, adult rats were fed egg albumin-based diets containing either lupin protein from Lupinus albus or casein $(50 \mathrm{~g} / \mathrm{kg})$ supplemented (hypercholesterolaemic) or not (normolipaemic) with a cholesterol-cholate mixture for $20 \mathrm{~d}$. Lupin protein compared with casein lowered the concentrations of TAG in liver $(P<0.01)$ and circulating VLDL + chylomicrons $(P<0 \cdot 05)$ of hypercholesterolaemic rats, but not of normolipaemic rats. Hepatic mRNA concentrations of genes involved in fatty acid synthesis such as sterol regulatory element-binding protein-1c, glucose-6-phosphate dehydrogenase, fatty acid synthase, stearoyl-CoA desaturase-1 and acyl-CoA:glycerol-3-phosphate acyltransferase were lower and mRNA concentrations of lipoprotein lipase, hepatic lipase and apoA5 involved in TAG hydrolysis were higher in rats fed lupin protein than in rats fed casein. These effects were stronger in hypercholesterolaemic rats than in normolipaemic rats. Hypercholesterolaemic rats fed the lupin protein had higher liver cholesterol concentrations $(P<0 \cdot 01)$ and lower levels of LDL-cholesterol $(P<0 \cdot 05)$ than rats fed casein. No effect of lupin protein was observed on cholesterol concentration in VLDL + chylomicrons and HDL and hepatic mRNA concentrations of genes involved in cholesterol and bile acid metabolism. In conclusion, the present study shows that lupin protein has hypotriacylglycerolaemic action possibly via down regulation of fatty acid synthesis genes and up regulation of genes involved in TAG hydrolysis. Alterations in cholesterol metabolism could not be explained on the basis of mRNA data.

Lupin protein: Liver lipids: Plasma lipoproteins: Hepatic gene expression: Rats

Grain legumes are a valuable source of food proteins. Soyabean protein is among the most important legume proteins used for human nutrition. Besides its nutritional value, soyabean protein has been known to exert hypocholesterolaemic $^{(1-6)}$ and hypotriacylglycerolaemic ${ }^{(5,7,8)}$ action in laboratory animals, pigs and human subjects when compared with casein. Another protein-rich legume besides soya is lupin which has been cultivated for centuries, mainly for domestic animal feed, but also for human nutrition. Nowadays, four Mediterranean species of lupin (Lupinus albus, L. angustifolius, L. luteus and L. mutabilis) are cultivated for nutrition and they are referred to as sweet lupins since they contain smaller amounts of toxic alkaloids than the bitter varieties. The protein and amino acid contents of lupin seeds and soya are very similar, but the amount of isoflavones is minimal in lupin ${ }^{(9,10)}$. Sirtori et al. ${ }^{(9)}$ have recently shown that lupin protein extract reduces cholesterolaemia in hypercholesterolaemic rats. These authors also found that lupin protein increases the activity of the LDL receptor in HepG2 cells, which could be an explanation for the hypocholesterolaemic effect observed in vivo. They also found a reduction of plasma TAG when hypercholesterolaemic rats were fed lupin protein, although possible mechanisms for the hypotriacylglycerolaemic effect have not been identified.

The present study was performed to gain further insights into the lipid-modulating effect of lupin protein. Since previous studies have found that the hypocholesterolaemic effect of soya is particularly evident in hypercholesterolaemic individuals, but is less consistently evident in normocholesterolaemic individuals (for a review, see Carroll ${ }^{(11)}$ ) we assume that the effect of lupin protein on lipid metabolism depends on the basal levels of circulating lipids. Hence, we tested the effects of lupin protein on lipid metabolism in rats fed a normolipaemic diet or a hypercholesterolaemic diet containing cholesterol and cholate. In most rat studies dealing with the effects of plant proteins on lipid metabolism the test protein was added to the diet in large amounts up to $25 \%$ as an exclusive protein source ${ }^{(7,8,12-14)}$. In the present study we decided to add the dietary test protein in an amount of $5 \%$ because we assume that those moderate amounts reflect the actual nutritional situation much better than large amounts. Adult rats were used for the present study because recent data on

Abbreviations: ABC, ATP-binding cassette transporter; ACAT, acyl-CoA cholesterol acyltransferase; CYP7A1, cholesterol 7 $\alpha$-hydroxylase; FAS, fatty acid synthase; GAPDH, glyceraldehyde-3-phosphate-dehydrogenase; GPAT, acyl-CoA:glycerol-3-phosphate acyltransferase; G6PDH, glucose-6-phosphate dehydrogenase; HL, hepatic lipase; HMG, 3-hydroxy-3-methylglutaryl; LCAT, lecithin:cholesterol acyltransferase; LPL, lipoprotein lipase; LXR, liver X receptor; SCD1, stearoyl-CoA desaturase-1; SREBP, sterol regulatory element-binding protein.

*Corresponding author: Professor Dr Gabriele Stangl, fax +49 345 5527124, email gabriele.stangl@landw.uni-halle.de 
the effects of rice protein on lipid metabolism of rats found a stronger lipid-lowering effect of the plant protein in adult rats weighing about $400 \mathrm{~g}$ than in growing rats weighing about $200 \mathrm{~g}^{(14)}$. Thus, adult rats seem to be an appropriate animal model for the study of protein effects on circulating lipids.

There are two major mechanisms by which lupin protein could act on lipid metabolism. First, lupin protein could act directly or indirectly on enzyme or receptor activities as shown in a recent study in which lupin protein stimulated LDL receptor activity ${ }^{(9)}$. Another possible mechanism includes the modulation of the transcription levels of genes involved in synthesis, uptake and degradation of lipids. A series of previous studies on the effects of soyabean protein or fish protein could demonstrate protein-specific effects on mRNA concentrations of hepatic genes ${ }^{(5,8,15)}$. It therefore seems likely that lupin protein may also influence lipid metabolism by influencing the transcript levels of genes.

Lipid homeostasis in vertebrate cells is mainly regulated by a family of membrane-bound transcription factors designated sterol regulatory element-binding proteins (SREBP). SREBP are transcription factors which directly activate the expression of more than thirty genes dedicated to the regulation of lipid levels ${ }^{(16-19)}$. While SREBP-2 is primarily responsible for the regulation of genes involved in cholesterol biosynthesis and uptake ${ }^{(20-22)}$, SREBP-1c is involved in the regulation of genes involved in fatty acid biosynthesis ${ }^{(23)}$. Recently, the consumption of isoflavone-poor soya protein was shown to reduce the plasma TAG concentration in rats, which was at least partially mediated by influencing gene expression or proteolytic activation of SREBP-1c in the liver ${ }^{(8)}$. This led us to the hypothesis that lupin protein could also act on hepatic lipid metabolism by influencing gene expression or proteolytic activation of SREBP. To test this hypothesis, we determined hepatic mRNA concentrations of SREBP-1c and 2, their corresponding target genes, as well as concentrations of circulating insulin and glucagon which are known to influence mRNA of SREBP-1c in the liver ${ }^{(24)}$.

However, there are also other genes not depending on SREBP activation which could be responsible for the dietary proteininduced alteration of TAG and cholesterol metabolism. These are genes that play a critical role in hydrolysis of circulating TAG such as lipoprotein lipase (LPL), hepatic lipase (HL) or apoA $5^{(25,26)}$ or PPAR $\alpha$-regulated genes involved in the oxidation of fatty acids such as carnitine palmitoyltransferase (CPT)-1a, acyl-CoA oxidase and cytochrome P450 (CYP)
4A1. Hepatic gene expression of cholesterol $7 \alpha$-hydroxylase (CYP7A1), liver $X$ receptor (LXR), ATP-binding cassette transporter (ABC)-A1, acyl-CoA cholesterol acyltransferase (ACAT), lecithin:cholesterol acyltransferase (LCAT), and class B type I scavenger receptor may also help to elaborate possible mechanisms by which lupin protein may influence lipid metabolism.

In brief, the aim of the present study was to assess possible lipid-lowering properties of protein isolated from white lupin and to elucidate whether lupin protein may alter the metabolism of lipids by influencing the transcript levels of genes involved in the regulation of TAG, cholesterol and bile acid pathways.

\section{Materials and methods}

\section{Animals and experimental diets}

The study was conducted as a two-factorial design. Forty-eight male Sprague-Dawley rats (Charles River, Sulzfeld, Germany) with an initial body weight of 464 (SD 21) g were randomly assigned to four groups of twelve rats each. All rats were kept individually in Macrolon cages in a room controlled for temperature $\left(22 \pm 2^{\circ} \mathrm{C}\right)$, relative humidity $(50-60 \%)$ and a $12 \mathrm{~h}-12 \mathrm{~h}$ light-dark cycle. All experimental procedures described followed established guidelines for the care and handling of laboratory animals and were approved by the council of Saxony-Anhalt, Germany.

All rats were fed two experimental semi-synthetic diets containing $200 \mathrm{~g}$ protein $/ \mathrm{kg}$ each. Two groups of rats received either a normolipaemic diet without additional cholesterol and cholate or a hypercholesterolaemic diet containing cholesterol $(10 \mathrm{~g} / \mathrm{kg})$ and sodium cholate $(5 \mathrm{~g} / \mathrm{kg})$ at the expense of cellulose. Each of these groups was fed either total lupin protein extract from L. albus $(50 \mathrm{~g} / \mathrm{kg})$ or casein $(50 \mathrm{~g} / \mathrm{kg})$ which served as the control protein. Each diet contained $150 \mathrm{~g}$ egg albumin $/ \mathrm{kg}$ in order to meet the amino acid requirements of the rats. The composition of the semi-synthetic diets is shown in Table 1. Vitamins and minerals were supplemented according to recommendations of the American Institute of Nutrition for rat diets ${ }^{(27)}$. Diet intake was controlled to avoid differences in food intake. The amount of food offered per d was slightly below the amount consumed ad libitum. Water was freely available from nipple drinkers. The experimental diets were fed for $20 \mathrm{~d}$.

Table 1. Composition of the experimental diets $(\mathrm{g} / \mathrm{kg})$

\begin{tabular}{|c|c|c|c|c|}
\hline & \multicolumn{2}{|c|}{ Normolipaemic diet } & \multicolumn{2}{|c|}{ Hypercholesterolaemic diet } \\
\hline & Casein diet & Lupin protein diet & Casein diet & Lupin protein diet \\
\hline Egg albumin & 150 & 150 & 150 & 150 \\
\hline Casein & 50 & - & 50 & - \\
\hline Lupin protein & - & 50 & - & 50 \\
\hline Maize starch & 390 & 390 & 390 & 390 \\
\hline Sucrose & 200 & 200 & 200 & 200 \\
\hline Lard & 100 & 100 & 100 & 100 \\
\hline Cellulose & 50 & 50 & 35 & 35 \\
\hline Vitamin and mineral mixture & 60 & 60 & 60 & 60 \\
\hline Cholesterol & - & - & 10 & 10 \\
\hline Sodium cholate & - & - & 5 & 5 \\
\hline
\end{tabular}




\section{Preparation and characterisation of the dietary proteins}

Casein was obtained from Meggle (Wasserburg, Germany) and was not further processed. The defatted total protein extract of $L$. albus was obtained from Fraunhofer Institute (IVV, Freising, Germany). The crude components of the dietary proteins were determined by official methods of Verband Deutscher Landwirtschaftlicher Untersuchungs- und Forschungsanstalten $^{(28)}$. DM content of the casein and lupin protein extract was 909 and $929 \mathrm{~g} / \mathrm{kg}$, respectively; the concentration of protein in DM was 939 and $960 \mathrm{~g} / \mathrm{kg}$, respectively. The fat and fibre content was low in both proteins (fat content $9 \mathrm{~g} / \mathrm{kg} \mathrm{DM}$ in casein, $11 \mathrm{~g} / \mathrm{kg} \mathrm{DM}$ in lupin protein; fibre content $4 \mathrm{~g} / \mathrm{kg}$ DM in casein, $3 \mathrm{~g} / \mathrm{kg} \mathrm{DM}$ in lupin protein). Concentrations of the isoflavones genistein, daidzein and genistin in the lupin protein were analysed by an HPLC $\operatorname{method}^{(29)}$. In brief, lupin protein was extracted with a mixture of methanol and dichloromethane $(1: 1, \mathrm{v} / \mathrm{v})$. After evaporation of the organic solvents, isoflavones were dissolved in $60 \%$ (v/ v) ethanol and used for a quantitative HPLC analysis of genistein, daidzein and genistin using an Agilent 1100 HPLC system equipped with a Hypersil ODS column $\left(250 \times 4 \mathrm{~mm}^{2} ; 5 \mu \mathrm{m}\right)$ at $40^{\circ} \mathrm{C}$ (Agilent Technologies, Waldbronn, Germany). A gradient of acetonitrile and $0.1 \%(\mathrm{v} / \mathrm{v})$ of trifluoroacetic acid in water from 1:9 (v/v) to $8: 2(\mathrm{v} / \mathrm{v})$ was used as the mobile phase at a flow rate of $0.8 \mathrm{ml} / \mathrm{min}$. Isoflavones were detected at $259 \mathrm{~nm}$. Genistein, daidzein and genistin concentrations of the lupin protein used in the study were below the detection limits of $2.22 \mu \mathrm{mol} / \mathrm{kg}$ for genistein, $1.18 \mu \mathrm{mol} / \mathrm{kg}$ for daidzein and $1.39 \mu \mathrm{mol} / \mathrm{kg}$ for genistin.

For analysis of the amino acid concentrations in the diets, samples were oxidised and then hydrolysed with $6 \mathrm{M}-\mathrm{HCl}^{(30)}$. Separation and quantification of the amino acids were performed by ion exchange chromatography following postcolumn derivatisation in an amino acid analyser (Biotronic LC 3000; Eppendorf, Hamburg, Germany). Tryptophan was measured after digesting the diets with barium hydroxide by reversed-phase HPLC $^{(31)}$. The concentrations of amino acids in the lupin protein and casein diets are shown in Table 2.

Table 2. Concentrations of amino acids in the experimental diets ( $\mathrm{g} / \mathrm{kg}$ diet)

\begin{tabular}{lrc} 
& Casein diet & Lupin protein diet \\
\hline Alanine & 9.5 & 9.6 \\
Arginine & 8.7 & 11.8 \\
Aspartic acid & $17 \cdot 2$ & 19.1 \\
Cysteine & 4.0 & 4.4 \\
Glutamic acid & 28.9 & 29.4 \\
Glycine & 5.7 & 6.6 \\
Histidine & 8.6 & $8 \cdot 1$ \\
Isoleucine & 8.8 & 8.9 \\
Leucine & 16.0 & 15.4 \\
Lysine & 12.4 & 10.6 \\
Methionine & 6.1 & 4.9 \\
Phenylalanine & 10.3 & 9.9 \\
Proline & 9.4 & 6.1 \\
Serine & 11.5 & 11.3 \\
Threonine & 7.9 & 7.4 \\
Tryptophan & 2.4 & 2.3 \\
Tyrosine & 6.7 & 7.0 \\
Valine & 11.3 & 9.9 \\
\hline
\end{tabular}

\section{Sample collection}

Rats were non-fasted before killing by decapitation under light anaesthesia with diethyl ether. The feeding was done to prevent starvation because it is known that food deprivation leads to a significant down regulation of genes encoding the enzymes of lipid metabolism ${ }^{(23)}$ which were to be measured in the present study. Plasma was separated from heparinised whole blood by centrifugation at $1500 \mathrm{~g}$ for $10 \mathrm{~min}$ at $4^{\circ} \mathrm{C}$. Liver was excised, weighed and immediately snap-frozen in liquid $\mathrm{N}_{2}$. Samples of liver for RNA isolation were stored at $-80^{\circ} \mathrm{C}$; other samples were stored at $-20^{\circ} \mathrm{C}$.

\section{Plasma and liver lipids}

Plasma lipoproteins VLDL + chylomicrons, LDL and HDL were separated by step-wise ultracentrifugation $\left(900000 \mathrm{~g}\right.$ at $4^{\circ} \mathrm{C}$ for $1.5 \mathrm{~h}$, Mikro-Ultrazentrifuge; Sorvall Products, Bad Homburg, Germany) ${ }^{(32)}$ using appropriate density cuts (VLDL + chylomicrons, $\rho<1.006 \mathrm{~kg} / \mathrm{l}$; LDL, $1.006 \mathrm{~kg} / \mathrm{l}<\rho<1.063 \mathrm{~kg} / \mathrm{l}$; HDL, $\rho>1.063 \mathrm{~kg} / \mathrm{l})^{(33)}$. Plasma densities were adjusted with sodium chloride and potassium bromide. Lipids from liver were extracted with a mixture of $n$-hexane and isopropanol $(3: 2, \mathrm{v} / \mathrm{v})^{(34)}$. For determination of the concentrations of lipids in liver, samples of the lipid extracts were dried and the lipids dissolved using Triton $\mathrm{X}-100^{(35)}$. Concentrations of cholesterol and TAG in plasma and lipoproteins and those of liver were determined using enzymic reagent kits (catalogue no. 1.13009990314 and 1.57609990314; DiaSys Diagnostic Systems, Holzheim, Germany).

\section{Measure of insulin and glucagon concentration in plasma}

Concentration of plasma insulin was determined by an enzyme-linked immunoassay using a commercially available rat insulin ELISA kit (EIA-2048; DRG Instruments, Marburg, Germany). The detection limit of insulin was $12.2 \mathrm{pmol} / \mathrm{l}$. The concentration of plasma glucagon was determined by RIA using a commercially available rat RIA kit (GL-32K; Linco Research, St Charles, MO, USA) with a detection limit of $5.8 \mathrm{pmol} / \mathrm{l}$.

\section{Real-time PCR analysis}

Total RNA was isolated from rat livers with TRIZOL ${ }^{\mathrm{TM}}$ reagent (Invitrogen, Karlsruhe, Germany) according to the manufacturer's protocol. RNA concentration and purity were estimated from the optical density at 260 and $280 \mathrm{~nm}$, respectively. Total RNA $(1.2 \mu \mathrm{g})$ was subjected to first-strand cDNA synthesis at $42^{\circ} \mathrm{C}$ for 60 min using M-MuLV RT (MBI Fermentas, St Leon-Rot, Germany) and oligo dT18-primer (Operon Biotechnologies, Cologne, Germany). The relative mRNA quantities of ABC-A1, ACAT (EC 2.3.1.38), acyl-CoA oxidase (EC 1.3.3.6), apoA5, carnitine palmitoyltransferase-1a (EC 2.3.1.2.1), cytochrome P450 4A1 (EC 1.14.15.3), CYP7A1 (EC 1.14.13.17), fatty acid synthase (FAS; $E C 2.3 .1 .65)$, glyceraldehyde-3-phosphate-dehydrogenase (GAPDH; EC 1.2.1.12), acyl-CoA:glycerol-3-phosphate acyltransferase (GPAT; EC 2.3.1.15), glucose-6-phosphate dehydrogenase (G6PDH; $E C$ 1.1.1.49), HL (EC 3.1.1.3), 3-hydroxy-3-methylglutaryl (HMG)-CoA reductase (EC 1.1.1.34), LCAT (EC 2.3.1.43), 
LDL receptor, LPL (EC 3.1.1.34), LXR, stearoyl-CoA desaturase-1 (SCD1; EC 1.14.19.1), class B type I scavenger receptor, SREBP-1c and SREBP-2 were measured by real-time detection PCR using SYBR ${ }^{\circledR}$ Green I (Sigma, Taufkirchen, Germany) and the Rotor Gene 2000 system (Corbett Research, Mortlake, Australia). Real-time detection PCR was performed with 1.25 U Taq DNA polymerase (Promega, Mannheim, Germany), 500 $\mu \mathrm{M}-\mathrm{dNTP}$ and $26.7 \mathrm{pmol}$ of the specific primers (Operon Biotechnologies). Sequences and annealing temperatures of the primers used for real-time PCR are presented in Table 3. For determination of mRNA concentration a threshold cycle $\left(C_{\mathrm{t}}\right)$ and amplification efficiency were obtained from each amplification curve using the software RotorGene $4 \cdot 6$ (Corbett Research). The housekeeping gene GAPDH was used for normalisation. The mRNA concentration of GAPDH was not influenced by experimental conditions.

\section{Statistics}

Data were analysed by two-way ANOVA using the Minitab Statistical Software (Minitab, State College, PA, USA). Classification factors were type of protein (lupin protein $v$. casein) and type of diet (normolipaemic diet $v$. hypercholesterolaemic diet), and the interaction of both factors (type of protein $\times$ type of diet). Levene's test was used to check for homoscedasticity. In cases, of unequal variances, logarithmic transformation was applied to obtain homogeneity of variances. $P$ values for treatment factors and interactions are reported, and the significance level was set at $P<0.05$. For significant interaction, individual means of the treatment groups were compared by Tukey's multiple comparison test. Means were considered significantly different at $P<0 \cdot 05$.

\section{Results}

Food intake, body and liver weights

Each rat received exactly $21.5 \mathrm{~g}$ food/d during the entire experimental period. Initial and final body weights were similar in all groups of rats (Table 4). Rats fed the hypercholesterolaemic diet had higher liver weights than animals fed the normolipaemic diet $(P<0 \cdot 01)$. Liver weight was not affected by the type of dietary protein (Table 4 ).

\section{Concentration of TAG in liver, plasma and lipoproteins}

There was a significant effect of the type of protein $(P<0 \cdot 01)$, and the type of diet $(P<0.01)$, and an interactive effect of both factors $(P<0 \cdot 01)$, on the concentration of TAG in liver (Table 4). Rats fed the hypercholesterolaemic diet had higher concentrations of TAG in liver than rats fed the normolipaemic diet. Among rats treated with the hypercholesterolaemic diet, lupin protein-fed animals had $45 \%$ lower TAG concentrations in their livers than rats fed casein. Among normolipaemic rats, lupin protein had no significant effect on TAG concentration in liver compared with casein.

Rats fed the hypercholesterolaemic diet had lower concentrations of plasma TAG than rats fed the normolipaemic diet $(P<0.01$; Table 4$)$. The type of protein did not influence plasma TAG, and there was no significant interaction between the type of protein and the type of diet on plasma TAG (Table 4). The concentration of TAG in VLDL + chylomicrons was influenced by the type of dietary protein $(P<0 \cdot 05)$, and there was an interaction between the type of protein and the type of diet $(P<0.01)$ on this parameter (Table 4). Hypercholesterolaemic rats fed lupin protein had $52 \%$ lower TAG concentrations in the VLDL + chylomicrons than hypercholesterolaemic rats

Table 3. Sequences and annealing temperatures of the primers used for real-time RT-PCR analysis

\begin{tabular}{|c|c|c|c|c|}
\hline Gene & Forward primer (from $5^{\prime}$ to $3^{\prime}$ ) & Reverse primer (from $5^{\prime}$ to $3^{\prime}$ ) & $\mathrm{bp}$ & Annealing temperature $\left({ }^{\circ} \mathrm{C}\right)$ \\
\hline ABC-A1 & GTTTTGGGGAGGAAATTGAT & AACCATCCACAGCAACCTTC & 162 & 60 \\
\hline ACAT & GCAACATTTCCGAACCATCT & GTCTGGTAGGGCAGAAGCAG & 201 & 60 \\
\hline ACO & СTTTCTTGСTTGCСTTCСTTСTCC & GCCGTTTCACCGCCTCGTA & 415 & 60 \\
\hline apoA5 & CAGACCCTGTCCCACAAACT & GGTCAATGGCCTGAGTGAAT & 235 & 60 \\
\hline CPT-1a & GGAGACAGACACCATCCAACATA & AGGTGATGGACTTGTCAAACC & 416 & 60 \\
\hline CYP4A1 & CAG AATGGAGAATGGGGACAGC & TGAGAAGGGCAGGAATGAGTGG & 460 & 65 \\
\hline CYP7A1 & CAAGACGCACCTCGCTATCC & CCGGCAGGTCATTCAGTTG & 206 & 60 \\
\hline FAS & AGGTGCTAGAGGCCCTGCTA & GTGCACAGACACCTTCCCAT & 281 & 60 \\
\hline GAPDH & GCATGGCCTTCCGTGTTCC & GGGTGGTCCAGGGTTTCTTACTC & 337 & 60 \\
\hline GPAT & CAGCGTGATTGCTACCTGAA & CTCTCCGTCCTGGTGAGAAG & 194 & 60 \\
\hline G6PDH & AGCCTCCTACAAGCACCTCA & TGGTTCGACAGTTGATTGGA & 213 & 60 \\
\hline $\mathrm{HL}$ & TCCCACCACAAGTACA & TCAGCCAGGGCATTATTTTC & 167 & 60 \\
\hline HMG-CoA reductase & AAGGGGCGTGCAAAGACAATC & ATACGGCACGGAAAGAACCATAGT & 406 & 57 \\
\hline LCAT & CTGGCTTTTGGCAAGACCTAC & TACCAGTCCTGCCAGCTTCT & 191 & 60 \\
\hline LDL receptor & AGAACTGCGGGGCCGAAGACAC & AAACCGCTGGGACATAGGCACTCA & 490 & 65 \\
\hline LPL & TCCCACCACAACGAAGTACA & TCAGCCAGGGCATTATTTTC & 205 & 60 \\
\hline LXR & TGATGCTGAATTTGCTCTGC & GGCTCACCAGCTTCATTAGC & 185 & 60 \\
\hline SCD1 & CCAGAGCGTACCAGCTTTTC & TTACCCACTTCGCAAGCTCT & 195 & 60 \\
\hline SR-BI & GGTGCCCATCATTTACCAAC & GCTTGCTTCTTGCAGTACC & 155 & 60 \\
\hline SREBP-1C & GGAGCCATGGATTGCACATT & AGGAAGGCTTCCAGAGAGGA & 191 & 60 \\
\hline SREBP-2 & ATCCGCCCACACTCACGCTCCTC & GGCCGCATCCCTCGCACTG & 214 & 65 \\
\hline
\end{tabular}

ABC, ATP-binding cassette transporter; ACAT, acyl-CoA cholesterol acyltransferase; ACO, acyl-CoA oxidase; CPT-1a, carnitine palmitoyltransferase 1a; CYP4A1, cytochrome P450 4A1; CYP7A1, cholesterol 7 $\alpha$-hydroxylase; FAS, fatty acid synthase; GAPDH, glyceraldehyde-3-phosphate-dehydrogenase; GPAT, acyl-CoA:glycerol-3-phosphate acyltransferase; G6PDH, glucose-6-phosphate dehydrogenase; HL, hepatic lipase; HMG-CoA, 3-hydroxy-3-methylglutaryl CoA; LCAT, lecithin:cholesterol acyltransferase; LPL, lipoprotein lipase; LXR, liver X receptor; SCD1, stearoyl-CoA desaturase-1; SR-BI, class B type I scavenger receptor; SREBP, sterol regulatory element-binding protein. 
Table 4. Body and liver weights, TAG and cholesterol concentrations in liver and plasma lipoproteins and plasma insulin and glucagon concentrations of rats fed normolipaemic or hypercholesterolaemic diets containing either casein or lupin protein

(Mean values and standard deviations for twelve rats per group)

\begin{tabular}{|c|c|c|c|c|c|c|c|c|c|c|c|}
\hline \multirow{3}{*}{$\begin{array}{l}\text { Type of diet... } \\
\text { Type of protein... }\end{array}$} & \multicolumn{4}{|c|}{ Normolipaemic } & \multicolumn{4}{|c|}{ Hypercholesterolaemic } & & & \\
\hline & \multicolumn{2}{|c|}{ Casein } & \multicolumn{2}{|c|}{ Lupin protein } & \multicolumn{2}{|c|}{ Casein } & \multicolumn{2}{|c|}{ Lupin protein } & \multicolumn{3}{|c|}{ Two-way ANOVA: $P$} \\
\hline & Mean & SD & Mean & SD & Mean & SD & Mean & SD & Protein & Diet & Protein $\times$ diet \\
\hline Body weight at day 1 (g) & 464 & 22 & 464 & 20 & 464 & 23 & 464 & 20 & NS & NS & NS \\
\hline Body weight at day $20(\mathrm{~g})$ & 506 & 21 & 502 & 19 & 504 & 24 & 506 & 23 & NS & NS & NS \\
\hline Liver weight (g) & $15 \cdot 3$ & $1 \cdot 1$ & $15 \cdot 0$ & 0.9 & $20 \cdot 1$ & $2 \cdot 2$ & 21.9 & $2 \cdot 7$ & NS & $<0.01$ & NS \\
\hline \multicolumn{12}{|l|}{ TAG } \\
\hline Liver $(\mu \mathrm{mol} / \mathrm{g})$ & $19 \cdot 1^{b, c}$ & 9.4 & $12 \cdot 7^{\mathrm{c}}$ & $2 \cdot 0$ & $55 \cdot 5^{\mathrm{a}}$ & $16 \cdot 2$ & $30 \cdot 4^{\mathrm{b}}$ & $11 \cdot 3$ & $<0.01$ & $<0.01$ & $<0.01$ \\
\hline Plasma (mmol/l) & 2.58 & 1.07 & $2 \cdot 80$ & 0.95 & 2.04 & 0.70 & 1.49 & 0.88 & NS & $<0.01$ & NS \\
\hline VLDL + chylomicrons $(\mathrm{mmol} / \mathrm{l})$ & $1.59^{\mathrm{a}}$ & 0.58 & $1.75^{\mathrm{a}}$ & 0.77 & $1.89^{\mathrm{a}}$ & 0.33 & $0.90^{\mathrm{b}}$ & 0.41 & $<0.05$ & NS & $<0.01$ \\
\hline \multicolumn{12}{|l|}{ Cholesterol } \\
\hline Liver $(\mu \mathrm{mol} / \mathrm{g})$ & $8.5^{\mathrm{c}}$ & $2 \cdot 8$ & $9.0^{\mathrm{C}}$ & 1.5 & $48 \cdot 8^{\mathrm{b}}$ & $12 \cdot 9$ & $74 \cdot 6^{\mathrm{a}}$ & 14.4 & $<0.01$ & $<0.01$ & $<0.05$ \\
\hline Plasma (mmol/l) & 2.08 & 0.40 & $2 \cdot 11$ & 0.32 & $4 \cdot 11$ & 0.88 & 4.57 & 1.30 & NS & $<0.01$ & NS \\
\hline VLDL + chylomicrons $(\mathrm{mmol} / \mathrm{l})$ & $0.20^{\mathrm{c}}$ & 0.10 & $0.23^{\mathrm{C}}$ & 0.11 & $1.73^{\mathrm{b}}$ & 0.53 & $2 \cdot 40^{\mathrm{a}}$ & 0.63 & NS & $<0.01$ & NS \\
\hline $\operatorname{LDL}(\mathrm{mmol} / \mathrm{l})$ & 0.83 & $0.27^{\mathrm{b}}$ & 0.70 & $0.28^{\mathrm{b}}$ & 1.39 & $0.60^{\mathrm{a}}$ & 0.83 & $0.30^{\mathrm{b}}$ & $<0.05$ & $<0.01$ & NS \\
\hline $\mathrm{HDL}(\mathrm{mmol} / \mathrm{l})$ & 1.07 & 0.38 & 1.19 & 0.42 & $1 \cdot 12$ & 0.78 & 1.61 & 0.77 & NS & NS & NS \\
\hline Plasma insulin (pmol//) & 90.1 & 24.5 & 110.5 & $36 \cdot 1$ & 94.7 & 33.0 & 95.5 & $33 \cdot 3$ & NS & NS & NS \\
\hline Plasma glucagon $(\mathrm{pmo} / \mathrm{l})$ & 13.6 & $5 \cdot 9$ & $10 \cdot 6$ & $5 \cdot 0$ & 14.4 & 4.7 & 12.9 & $7 \cdot 0$ & NS & NS & NS \\
\hline
\end{tabular}

${ }^{a, b, c}$ Mean values within a row with unlike superscript letters are significantly different $(P<0.05$; Tukey's multiple comparison test $)$. 
fed casein. Lupin protein compared with casein had no effect on the concentration of VLDL + chylomicron TAG in rats fed the normolipaemic diet. The type of diet did not influence the concentrations of TAG in VLDL + chylomicrons (Table 4).

\section{Concentration of cholesterol in liver, plasma and lipoproteins}

There was a significant effect of the type of protein $(P<0.01)$ and the type of diet $(P<0 \cdot 01)$, and a significant interactive effect of both factors $(P<0 \cdot 05)$ on the concentration of cholesterol in liver (Table 4). Rats fed the hypercholesterolaemic diet had higher liver cholesterol concentrations than rats fed the normolipaemic diet. Hypercholesterolaemic rats fed lupin protein had $53 \%$ higher concentrations of cholesterol in liver than hypercholesterolaemic rats fed casein (Table 4). Lupin protein did not alter the liver cholesterol concentration in rats fed the normolipaemic diet.

The concentration of cholesterol in plasma was influenced by the type of diet and was higher in rats fed the hypercholesterolaemic diet than in rats fed the normolipaemic diet $(P<0.01$; Table 4$)$. The type of protein did not influence the concentration of plasma cholesterol; no interaction between the type of protein and the type of diet was observed (Table 4).

Lupin protein did not alter the concentration of cholesterol in VLDL + chylomicrons (Table 4). The concentration of cholesterol in VLDL + chylomicrons was significantly higher in rats fed the hypercholesterolaemic diet than in rats fed the normolipaemic diet $(P<0.01$; Table 4$)$. No interaction between the type of protein and the type of diet was observed.

The concentration of LDL-cholesterol was influenced by the type of protein $(P<0.05)$ and the type of $\operatorname{diet}(P<0.01)$, but no interaction between these two factors was observed (Table 4). Rats fed the hypercholesterolaemic diet had higher concentrations of LDL-cholesterol than rats fed the normolipaemic diet (Table 4). Lupin protein lowered the concentration of LDL-cholesterol compared with casein (Table 4).

The concentration of HDL-cholesterol was not influenced by the type of protein or the type of diet (Table 4).

\section{Concentrations of insulin and glucagon in plasma}

The concentrations of insulin and glucagon in rat plasma were not influenced by the type of dietary protein or the type of diet (Table 4).

Hepatic mRNA concentrations of genes involved in fatty acid synthesis

The relative concentration of the transcription factor SREBP$1 \mathrm{c}$ in liver was influenced by the type of protein $(P<0.01)$ and the type of diet $(P<0 \cdot 01)$, and there was an interaction between these two factors $(P<0 \cdot 05$; Fig. 1$)$. The hypercholesterolaemic diet increased hepatic mRNA levels of SREBP-1c compared with a normolipaemic diet when rats were fed casein, but not when rats were fed lupin protein. Lupin protein compared with casein lowered the mRNA level of hepatic SREBP-1c in hypercholesterolaemic rats but not in normolipaemic rats. Lupin protein down regulated the relative mRNA concentrations of the SREBP-1c target genes G6PDH $(P<0.05)$, FAS $(P<0.01)$, SCD1 $(P<0.01)$ and GPAT $(P<0.01)$ compared with casein (Fig. 1). Rats fed the hypercholesterolaemic diet had higher mRNA levels of SCD1 $(P<0.05)$ and GPAT $(P<0.05)$ than rats fed the normolipaemic diet. Relative mRNA concentrations of G6PDH and FAS were not influenced by the type of diet. No interaction between these two factors on the SREBP-1c target genes was observed.

\section{Hepatic mRNA concentrations of genes involved in TAG} hydrolysis

There was a significant effect of the type of protein on the mRNA concentrations of LPL $(P<0 \cdot 05)$, HL $(P<0 \cdot 01)$ and apoA5 $(P<0.01)$ in liver, which were up regulated in rats fed lupin protein compared with rats fed casein (Fig. 2). The relative mRNA concentration of $\mathrm{HL}$ was up regulated in rats fed the hypercholesterolaemic diet compared with rats fed the normolipaemic diet $(P<0.01$; Fig. 2$)$. The mRNA concentrations of LPL and apoA5 were not influenced by the type of diet. There was also no interaction between the type of protein and the type of diet on any of these genes.

\section{Hepatic mRNA concentrations of PPAR $\alpha$-regulated genes involved in fatty acid oxidation}

There was no effect of the type of protein and the type of diet on the mRNA concentrations of acyl-CoA oxidase, carnitine palmitoyltransferase-1a, and cytochrome P450 4A1 (Table 5).

Hepatic mRNA concentrations of genes involved in cholesterol and bile acid metabolism

Hepatic mRNA concentrations of ABC-A1 $(P<0.05)$, ACAT $(P<0.01)$, CYP7A1 $(P<0.01)$, LXR $(P<0.05)$ and SR-B1 $(P<0 \cdot 01)$ were higher in groups fed the hypercholesterolaemic diet than in groups fed the normolipaemic diet (Table 5). Rats treated with the hypercholesterolaemic diet had about $35 \%$ lower hepatic mRNA concentrations of HMG-CoA reductase than rats fed the normolipaemic diet $(P<0.05$; Table 5). Relative mRNA concentrations of LCAT, LDL receptor and SREBP-2 remained unaffected by the type of diet (Table 5). When rats were fed the lupin protein the mRNA concentration of SR-B1 $(P<0 \cdot 01)$ was lower and the mRNA concentration of ABC-A1 $(P<0.01)$ was higher compared with rats fed casein (Table 5). Relative mRNA concentrations of ACAT, CYP7A1, HMG-CoA reductase, LCAT, LDL receptor, LXR and SREBP-2 remained unaffected by the dietary protein (Table 5). There were no interactive effects of both factors on the hepatic mRNA concentrations of any of these genes (Table 5).

\section{Discussion}

In the present study we were able to demonstrate that lupin protein significantly lowers the concentrations of TAG in the liver and TAG-rich lipoproteins compared with casein. The hypotriacylglycerolaemic effect of lupin protein on VLDL + chylomicrons was observed in hypercholesterolaemic but not in normolipaemic rats. Although the reduction of TAG concentration in VLDL + chylomicrons of hypercholesterolaemic rats fed lupin protein was not reflected in a statistically significant reduction of TAG in plasma, it can be stated that 

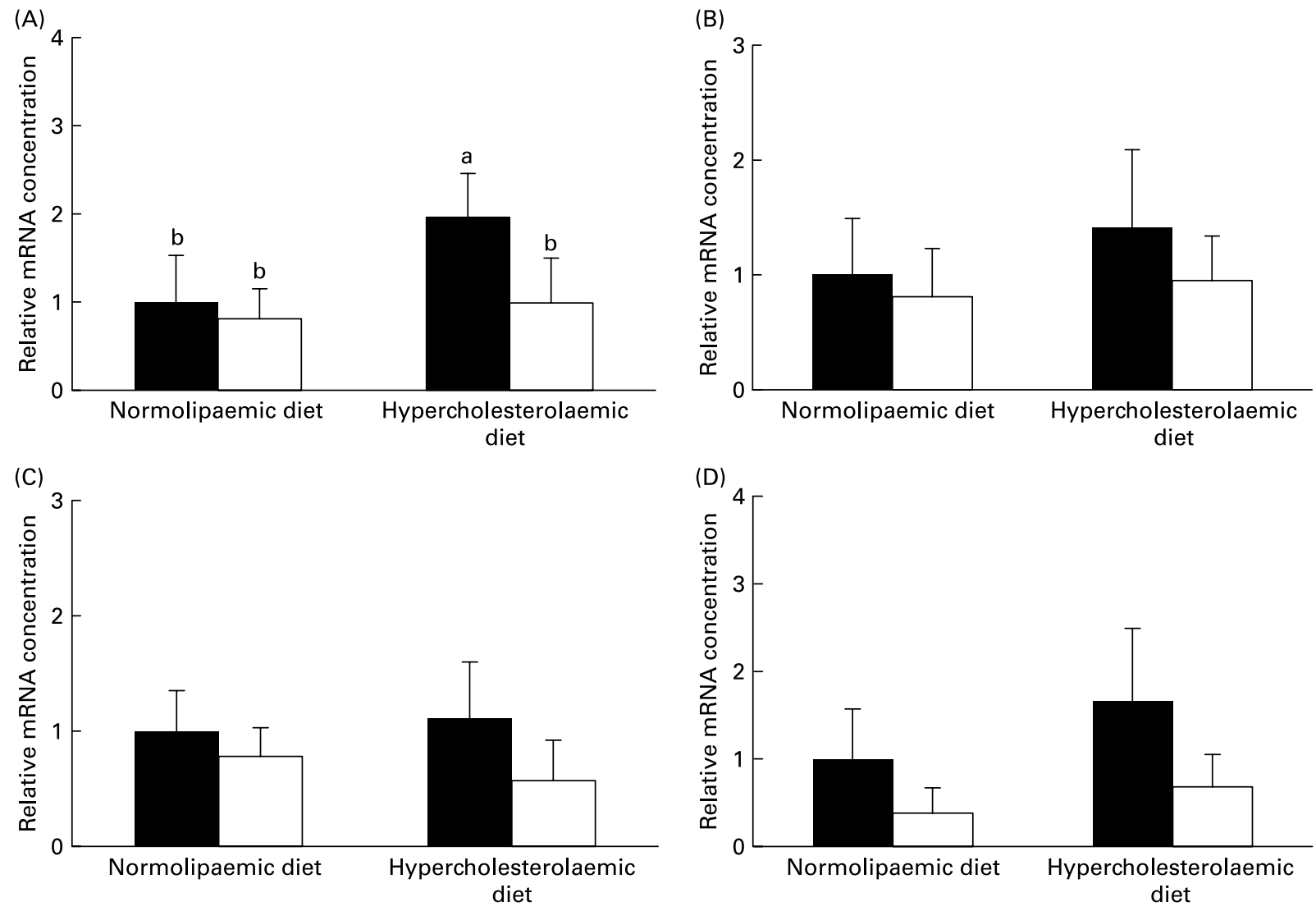

(E)



Fig. 1. Effect of lupin protein $(\square)$ compared with casein ( $\square)$ on the relative mRNA concentrations of genes involved in fatty acid synthesis in the liver of rats fed a normolipaemic or hypercholesterolaemic diet: sterol regulatory element-binding protein (SREBP)-1c (A); glucose-6-phosphate dehydrogenase (G6PDH) (B); fatty acid synthase (FAS) (C); stearoyl-CoA desaturase (SCD)-1 (D); acyl-CoA:glycerol-3-phosphate acyltransferase (GPAT) (E). Total RNA was extracted from rat livers and SREBP-1c, G6PDH, FAS, SCD1 and GPAT mRNA concentrations were determined by real-time detection RT-PCR analysis using glyceraldehyde-3phosphate-dehydrogenase mRNA concentration for normalisation. mRNA concentrations of the genes are shown relative to those of rats fed the normolipaemic diet with casein $(=1.00)$. Data were analysed by two-way ANOVA. Classification factors were type of protein (protein), type of diet (diet) and the interaction between both factors (protein $\times$ diet). For significant interaction, individual means of the treatment groups were compared by Tukey's multiple comparison test. Values are means $(n 12)$, with standard deviations represented by vertical bars. For SREBP-1c, the effect of protein was significant $(P<0.01)$, the effect of diet was significant $(P<0.01)$ and the effect of protein $\times$ diet was significant $(P<0.05)$. For $\mathrm{G} 6 \mathrm{PDH}$, the effect of protein was significant $(P<0.05)$; the effects of diet and protein $\times$ diet were NS $(P>0.05)$. For FAS, the effect of protein was significant $(P<0.01)$; the effects of diet and protein $\times$ diet were NS $(P>0.05)$. For SCD1, the effect of protein was significant $(P<0.01)$, the effect of diet was significant $(P<0.05)$ and the effect of protein $\times$ diet was NS $(P>0.05)$. For GPAT, the effect of protein was significant $(P<0.01)$, the effect of diet was significant $(P<0.05)$ and the effect of protein $\times$ diet was NS $(P>0.05)$. ${ }^{\text {a,b }}$ Values with unlike letters are significantly different $(P<0.05$; Tukey's multiple comparison test).

lupin protein has hypotriacylglycerolaemic action in rats fed a hypercholesterolaemic diet. This supports the recent finding of Sirtori et al. ${ }^{(9)}$ where lupin protein was capable of lowering circulating TAG in rats fed a hypercholesterolaemic diet. It is possible that larger amounts of lupin protein up to $20 \%$ in the diet would have lowered the concentration of TAG more strongly than $5 \%$ and that this reduction would have been reflected in reduced levels of plasma TAG. Our gene expression data strongly suggest that the TAG-lowering effect of lupin protein might be caused by an alteration of 

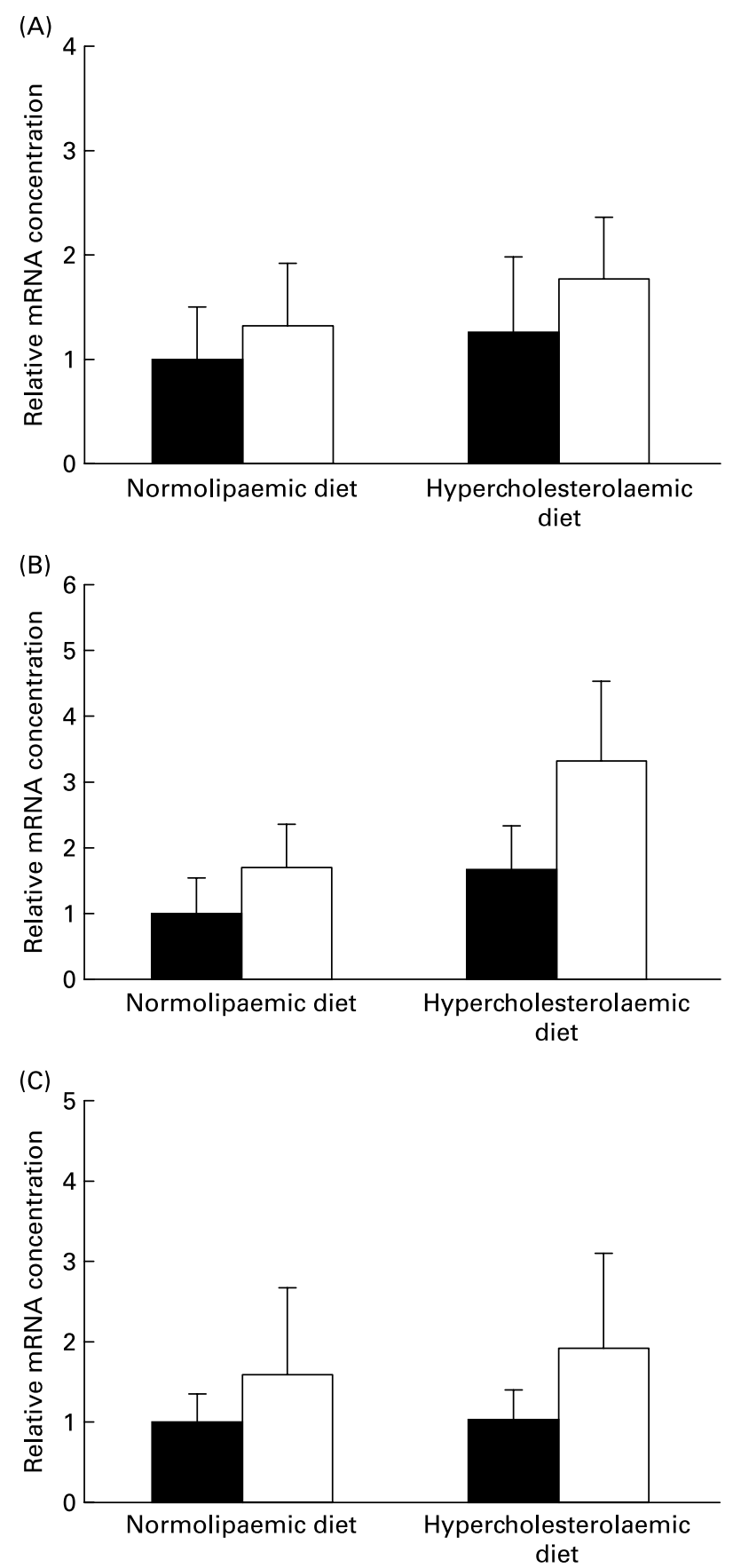

Fig. 2. Effect of lupin protein ( $\square$ ) compared with casein ( $\square$ ) on the relative mRNA concentrations of genes involved in TAG hydrolysis in the liver of rats fed a normolipaemic or hypercholesterolaemic diet: lipoprotein lipase $(\mathrm{LPL})(\mathrm{A})$; hepatic lipase $(\mathrm{HL})(\mathrm{B})$; apoA5 (C). Total RNA was extracted from rat livers and $\mathrm{LPL}, \mathrm{HL}$ and apoA5 mRNA concentrations were determined by real-time detection RT-PCR analysis using glyceraldehyde-3-phosphate-dehydrogenase mRNA concentration for normalisation. mRNA concentrations of the genes are shown relative to those of rats fed the normolipaemic diet with casein $(=1 \cdot 00)$. Data were analysed by two-way ANOVA. Classification factors were type of protein (protein), type of diet (diet) and the interaction between both factors (protein $\times$ diet). Values are means ( $n$ 12), with standard deviations represented by vertical bars. For $\mathrm{LPL}$, the effect of protein was significant $(P<0.05)$; the effects of diet and protein $\times$ diet were NS $(P>0.05)$. For $\mathrm{HL}$, the effects of protein and diet were significant $(P<0.01)$; the effect of protein $\times$ diet was NS $(P>0.05)$. For apoA5, the effect of protein was significant $(P<0.001)$; the effects of diet and protein $\times$ diet were NS $(P>0.05)$.
mRNA transcript levels of genes involved in the de novo synthesis of fatty acids, as well as genes associated with TAG hydrolysis. SREBP-1c, a well-known key regulator of fatty acid and TAG synthesis in the liver by activation of the transcription of genes encoding fatty acid synthesis enzymes $^{(23)}$, was down regulated by lupin protein in the present study. Although we did not measure the mature fraction of SREBP-1c in the nucleus, the reduced expression of the SREBP-1c-regulated genes G6PDH, FAS, SCD1 and GPAT strongly suggests a diminished lipogenesis via SREBP-1c. The present study therefore proposes that lupin protein lowered fatty acid synthesis in the liver compared with casein by inhibiting the SREBP-1c-mediated gene expression of lipogenic enzymes. The down regulation of G6PDH, FAS, SCD1 and GPAT in the liver of lupin protein-fed rats was stronger in rats fed the hypercholesterolaemic diet than in rats fed the normolipaemic diet, and could be the reason for the hypotriacylglycerolaemic effect of lupin protein in hypercholesterolaemic rats, but not in normolipaemic rats. The observed effect of lupin protein on SREBP-1c-regulated genes is consistent with previous findings on the effects of soya protein ${ }^{(3,7,8,36,37)}$. Soya and lupin belong to the same plant family and were characterised by a similar protein content and composition. The main difference between lupin seeds and soya beans are the amounts of isoflavones, which were shown to be extremely low in the lupin protein isolate used for the present study compared with the relatively high amounts that usually occur in soya protein. Based on these data, we may conclude that the effect of legumes on TAG metabolism is primarily caused by the protein itself, rather than by the isoflavones.

Recent evidence shows that key genes involved in TAG homeostasis such as SREBP-1c are regulated by insulin ${ }^{(24)}$ and findings of Ascencio et al. ${ }^{(7)}$ indicate that soya protein down regulates SREBP-1c expression by modulating insulin concentration and the insulin:glucagon-ratio in serum. However, significant differences in plasma concentration of insulin and glucagon were not observed in the present study, although we are aware of the fact that a single measure of the hormone concentrations could not be as conclusive as the measurement of plasma insulin and glucagon at defined time-intervals after food according to a fixed time schedule and the determination of the areas under the insulin and glucagon curves.

The ability of lupin protein to down regulate mRNA levels of genes involved in fatty acid and TAG synthesis provides a plausible mechanism for the TAG-lowering effect. Another mechanism which might be responsible for the hypotriacylglycerolaemic action of lupin protein is the observed up regulation of mRNA coding for LPL, HL and apoA5. This effect was also stronger in hypercholesterolaemic rats than in normolipaemic rats. Each of these genes is involved in TAG hydrolyses. LPL catalyses the hydrolysis of TAG of circulating chylomicrons and VLDL. Although LPL is considered to be mainly an extrahepatic enzyme we can speculate that the observed up regulation of LPL mRNA concentration in the liver may also occur in other tissues. Besides its classical function, LPL can perform a non-catalytic bridging function that allows it to bind simultaneously to both lipoproteins and specific cell-surface proteins, including receptors for LDL and VLDL (for a review, see Goldberg ${ }^{(38)}$ ). HL, the second enzyme up regulated by lupin protein, also functions as a lipolytic enzyme that hydrolyses TAG and phospholipids present 
Table 5. Relative mRNA concentrations of hepatic genes involved in lipid metabolism of rats fed normolipaemic or hypercholesterolaemic diets containing either casein or lupin protein*

(Mean values and standard deviations for twelve rats per group)

\begin{tabular}{|c|c|c|c|c|c|c|c|c|c|c|c|}
\hline \multirow{3}{*}{$\begin{array}{l}\text { Type of diet... } \\
\text { Type of protein... }\end{array}$} & \multicolumn{4}{|c|}{ Normolipaemic } & \multicolumn{4}{|c|}{ Hypercholesterolaemic } & & & \\
\hline & \multicolumn{2}{|c|}{ Casein } & \multicolumn{2}{|c|}{ Lupin protein } & \multicolumn{2}{|c|}{ Casein } & \multicolumn{2}{|c|}{ Lupin protein } & \multicolumn{3}{|c|}{ Two-way ANOVA: $P$} \\
\hline & Mean & SD & Mean & SD & Mean & SD & Mean & SD & Protein & Diet & Protein $\times$ diet \\
\hline $\mathrm{ABC}-\mathrm{A} 1$ & 1.00 & 0.47 & $1 \cdot 38$ & 0.54 & $1 \cdot 21$ & 0.32 & $1 \cdot 78$ & 0.55 & $<0.01$ & $<0.05$ & NS \\
\hline ACAT & 1.00 & 0.61 & 0.90 & 0.34 & $1 \cdot 36$ & 0.37 & $1 \cdot 34$ & 0.52 & NS & $<0.01$ & NS \\
\hline $\mathrm{ACO}$ & 1.00 & 0.32 & 1.01 & 0.35 & 1.15 & 0.68 & 0.99 & 0.44 & NS & NS & NS \\
\hline CPT-1a & 1.00 & 0.88 & 0.62 & 0.51 & 0.72 & 0.89 & $1 \cdot 23$ & 1.43 & NS & NS & NS \\
\hline CYP4A1 & 1.00 & 0.52 & 0.75 & 0.55 & 0.60 & 0.60 & 0.48 & 0.51 & NS & NS & NS \\
\hline CYP7A1 & 1.00 & 0.66 & 0.92 & 0.59 & $2 \cdot 29$ & 0.79 & $1 \cdot .39$ & 1.04 & NS & $<0.01$ & NS \\
\hline HMG-CoA reductase & 1.00 & 0.82 & 0.72 & 0.37 & 0.36 & 0.23 & 0.27 & 0.15 & NS & $<0.05$ & NS \\
\hline LCAT & 1.00 & 0.42 & $1 \cdot 21$ & 0.43 & $1 \cdot 15$ & 0.45 & 1.45 & 0.45 & NS & NS & NS \\
\hline LDL receptor & 1.00 & 0.63 & 0.93 & 0.54 & 0.60 & 0.41 & 0.72 & 0.15 & NS & NS & NS \\
\hline LXR & 1.00 & 0.19 & 1.08 & 0.48 & $1 \cdot 38$ & 0.60 & 1.24 & 0.45 & NS & $<0.05$ & NS \\
\hline SR-B1 & 1.00 & 0.58 & 0.49 & 0.25 & 1.48 & 0.49 & 0.81 & 0.39 & $<0.01$ & $<0.01$ & NS \\
\hline SREBP-2 & 1.00 & 0.88 & 0.91 & 0.41 & 0.60 & 0.27 & 0.62 & 0.33 & NS & NS & NS \\
\hline
\end{tabular}

ABC, ATP-binding cassette transporter; ACAT, acyl-CoA cholesterol acyltransferase; ACO, acyl-CoA oxidase; CPT-1a, carnitine palmitoyltransferase-1a; CYP4A1, cytochrome P450 4A1; CYP7A1, cholesterol 7 $\alpha$-hydroxylase; HMG-CoA, 3-hydroxy-3-methylglutaryl CoA; LCAT, lecithin:cholesterol acyltransferase; LXR, liver X receptor; SR-BI, class $B$ type I scavenger receptor; SREBP, sterol regulatory element-binding protein.

* Total RNA was extracted from livers and mRNA concentrations were determined by real-time detection RT-PCR analysis using glyceraldehyde-3-phosphate-dehydrogenase mRNA concentration for normalisation. mRNA concentrations of the genes are shown relative to the livers of rats fed the normolipaemic diet with casein $(=1.00)$.

in circulating plasma lipoproteins and, similar to LPL, it also serves as a ligand facilitating lipoprotein uptake by cell-surface receptors ${ }^{(26)}$. In vitro studies have demonstrated that HL enhances the binding or uptake of chylomicrons, VLDL, $\mathrm{LDL}^{(39)}$ and HDL-cholesterol ${ }^{(40,41)}$. Another gene up regulated by lupin protein was apoA5, a newly identified apolipoprotein which is predominantly expressed in the liver. It is an important determinant of plasma TAG levels and has been found to accelerate VLDL catabolism by activating intravascular TAG hydrolysis via enhancement of binding between lipoproteins and proteoglycans at the vascular wall and activation of proteoglycan-bound $\mathrm{LPL}^{(42)}$ and enhancing VLDL removal from the plasma ${ }^{(43-45)}$. The findings of the present study strongly suggest that lupin protein not only down regulates genes involved in fatty acid synthesis, but also accelerates TAG degradation in plasma via up regulation of genes responsible for TAG hydrolysis and uptake.

Although we do not know by what mechanism lupin protein increases the mRNA levels of these genes, it is possible that the up regulation of apoA5 was caused by the down regulated SREBP-1c, since SREBP-1c has recently been reported to down regulate apoA5 gene expression by binding directly to the functional E-box in the promoter ${ }^{(46)}$. It is further known that activation of PPAR $\alpha$ is related to up regulation of apoA $5^{(47,48)}$. However, we suggest that PPAR $\alpha$ activation can be ruled out as a potential cause of the increased apoA5 mRNA levels because data of the present study show that mRNA concentration of PPAR $\alpha$ target genes such as carnitine palmitoyltransferase-1a, cytochrome P450 4A1 and acyl-CoA oxidase were not altered by the dietary protein.

Another interesting result from the present study was the effect of lupin protein on cholesterol metabolism of rats fed the hypercholesterolaemic diet. The concentration of cholesterol in liver was significantly increased in response to the lupin protein compared with casein, whilst the concentration of LDL-cholesterol in plasma was reduced. However, it is difficult to compare the present results with those obtained from a recent lupin study by Sirtori et al. ${ }^{(9)}$ because in that study lipoprotein cholesterol was demonstrated as LDL- plus VLDL-cholesterol. We are also aware of the fact that in rats fed high amounts of cholesterol the lipoprotein fraction with a density between 1.006 and $1.063 \mathrm{~kg} / \mathrm{l}$ contained not only LDL but also HDL, which predominantly appeared in the fraction at a density between 1.006 and $1.030 \mathrm{~kg} / \mathrm{l}$ together with the LDL, while in normolipaemic rats most of the LDLcholesterol appeared in the fraction at the density between 1.030 and $1.063 \mathrm{~kg} / \mathrm{l}^{(49)}$. Due to the fact that a characterisation of the plasma lipoproteins on the basis of density classes is of only limited validity, further studies in which the concentrations of apolipoproteins will be measured are necessary to assess the effect of proteins on atherogenic or non-atherogenic lipoproteins. In order to examine possible mechanisms for the lupin protein-mediated alterations of the cholesterol levels in liver and lipoproteins we measured the mRNA concentration of genes involved in cholesterol synthesis, cholesterol uptake, reverse cholesterol transport and bile acid synthesis. The LDL receptor is a major regulator of circulating LDLcholesterol $^{(50)}$. Sirtori et al. ${ }^{(9)}$ have observed that protein from white lupin seed has hypocholesterolaemic action which might result from a stimulation of LDL receptor activity. The present study shows, however, that the LDL receptor was not altered at transcription level in response to the dietary lupin protein. A failing effect of lupin protein was also observed with HMG-CoA reductase, the key enzyme for cholesterol synthesis. Gene expression of LDL receptor and HMG-CoA reductase is SREBP-2 regulated $^{(20-22)}$, and the failing effect of lupin protein on expression of these genes is in contrast to a recent study with soyabean protein showing a strong reduction of SREBP-2, LDL receptor and HMG-CoA reductase in normolipaemic rats fed an isoflavone-poor soya protein compared with rats fed $\operatorname{casein}^{(8)}$. Moreover, other genes involved in cholesterol metabolism such as LCAT and ACAT were also not influenced at transcription levels by the lupin protein. 
We found that lupin protein had a significant up regulating effect on the mRNA concentrations of LPL and ABC-A1. Both are target genes of LXR and an increase of mRNA concentration of LPL and ABC-A1 could possibly reflect LXR activation. LXR has been identified as a positive regulator of CYP7A1 transcription, the initial and rate-limiting enzyme in conversion of cholesterol to $7 \alpha$-hydroxylated bile acids ${ }^{(51)}$. The failing effect of lupin protein on mRNA of CYP7A1 together with the increased cholesterol concentration in livers of hypercholesterolaemic rats fed lupin protein are not indicative of stimulated bile acid formation. However, further studies have to be done in order to elucidate the bile acid excretion in response to feeding lupin protein.

In conclusion, the present study shows that lupin protein compared with casein had a TAG-lowering effect on plasma lipoproteins and liver which is at least in part mediated by down regulation of genes responsible for fatty acid synthesis and by up regulation of genes involved in TAG hydrolysis. The increased concentration of cholesterol in liver and the lower levels of LDL-cholesterol in rats fed the lupin protein compared with rats fed casein could not be explained on the basis of mRNA data. Possible mechanisms should therefore be elucidated in further studies. The observed reductions of circulating TAG and LDL-cholesterol in hypercholesterolaemic rats fed lupin protein compared with rats fed casein suggest possible health-promoting properties of lupin protein. The increased concentration of cholesterol in the liver observed in hypercholesterolaemic rats fed lupin protein together with reported cases of lupin allergy in humans, either as lupin allergy or as cross-reactivity to other legumes, especially groundnuts ${ }^{(52,53)}$, could possibly limit the beneficial effect of lupin protein.

\section{Acknowledgements}

A. B. carried out the animal experiment, determined the mRNA concentrations of the hepatic genes, participated in the interpretation of the results and prepared the manuscript. C. B. planned the animal experiment and supervised the lipid and hormone analyses; K. W. analysed the isoflavone concentrations of the lupin protein; F. H. supervised the amino acid analysis; K. E. participated in the design of the study and interpretation of the results; G. I. S. conceived of the study and its design, coordinated work, participated in the interpretation of the results and helped to draft the manuscript. The research was supported by a grant from the Bundesministerium für Wirtschaft und Arbeit (BMWA). There is not any potential conflict of interest.

\section{References}

1. Anderson JW, Johnstone BM \& Cook-Newell ME (1995) Metaanalysis of the effects of soybean protein intake on serum lipids. $N$ Engl J Med 333, 276-282.

2. Sirtori CR, Lovati MR, Manzoni C, Monetti M, Pazzucconi F \& Gatti E (1995) Soy and cholesterol reduction: clinical experience. J Nutr 125, Suppl. 3, 598S-605S.

3. Iritani N, Hosomi H, Fukuda H, Tada K \& Ikeda H (1996) Soybean protein suppresses hepatic lipogenic enzyme gene expression in Wistar fatty rats. J Nutr 126, 380-388.
4. Sirtori CR, Lovati MR, Manzoni C, Gianazza E, Bondioli A, Staels B \& Auwerx J (1998) Reduction of serum cholesterol by soybean proteins: clinical experience and potential molecular mechanisms. Nutr Metab Cardiovasc Dis 8, 334-340.

5. Tovar AR, Murguía F, Cruz C, Hernández-Pando R, Aguilar-Salinas CA, Pedraza-Chaverri J, Correa-Rotter R \& Torres N (2002) A soy protein diet alters hepatic lipid metabolism gene expression and reduces serum lipids and renal fibrogenic cytokines in rats with chronic nephritic syndrome. J Nutr 132, 2562-2569.

6. Koba K, Liu JW, Bobik E Jr, Mills DE, Sugano M \& Huang YS (2003) Effect of phytate in soy protein on the serum and liver cholesterol levels and fatty acid profile in rats. Biosci Biotechnol Biochem 67, 15-22.

7. Ascencio C, Torres N, Isoard-Acosta F, Gómez-Pérez FJ, Hernández-Pando R \& Tovar AR (2004) Soy protein affects serum insulin and hepatic SREBP-1 mRNA and reduces fatty liver in rats. $J$ Nutr 134, 522-529.

8. Shukla A, Brandsch C, Bettzieche A, Hirche F, Stangl GI \& Eder K (2007) Isoflavone-poor soy protein alters the lipid metabolism of rats by SREBP-mediated down-regulation of hepatic genes. J Nutr Biochem 18, 313-321.

9. Sirtori CR, Lovati MR, Manzoni C, Castiglioni S, Duranti M, Magni C, Moranti S, D'Agostina A \& Arnoldi A (2004) Proteins of white lupin seed, a naturally isoflavone-poor legume, reduce cholesterolemia in rats and increase LDL receptor activity in HepG2 cells. $J$ Nutr 134, 18-23.

10. Wait R, Gianazza E, Brambilla D, Eberini I, Morandi S, Arnoldi A \& Sirtori CR (2005) Analysis of Lupinus albus storage proteins by two-dimensional electrophoresis and mass spectrometry. J Agric Food Chem 53, 4599-4606.

11. Carroll KK (1991) Review of clinical studies on cholesterollowering response to soy protein. J Am Diet Assoc 91, 820-827.

12. Madani S, Lopez S, Blond JP, Prost J \& Belleville J (1998) Highly purified soybean protein is not hypocholesterolemic in rats but stimulates cholesterol synthesis and excretion and reduces polyunsaturated fatty acid biosynthesis. J Nutr 128, 1084-1091.

13. Tovar AR, Torre-Villalvazo I, Ochoa M, Elias AL, Ortiz V, Aguilar-Salinas CA \& Torres N (2005) Soy protein reduces hepatic lipotoxicity in hyperinsulinemic obese Zucker fa/fa rats. J Lipid Res 46, 1823-1832.

14. Yang L, Kumagai T, Kawamura H, Watanabe T, Kubota M, Fujimura S, Watanabe R \& Kadowaki M (2007) Effects of rice proteins from two cultivars, Koshihikari and Shunyo, on cholesterol and triglyceride metabolism in growing and adult rats. Biosci Biotechnol Biochem 71, 694-703.

15. Mullen E, Brown RM, Osborne TF \& Shay NF (2004) Soy isoflavones affect sterol regulatory element binding proteins (SREBPs) and SREBP-regulated genes in HepG2 cells. $J$ Nutr 134, 2942-2947.

16. Brown MS \& Goldstein JL (1997) The SREBP pathway: regulation of cholesterol metabolism by proteolysis of a membrane-bound transcription factor. Cell 89, 331-340.

17. Horton JD \& Shimomura I (1999) Sterol regulatory elementbinding proteins: activators of cholesterol and fatty acid biosynthesis. Curr Opin Lipidol 10, 143-150.

18. Edwards PA, Tabor D, Kast HR \& Venkateswaran A (2000) Regulation of gene expression by SREBP and SCAP. Biochim Biophys Acta 1529, 103-113.

19. Sakakura Y, Shimano H, Sone H, Takahashi A, Inoue N, Toyoshima H, Suzuki S \& Yamada N (2001) Sterol regulatory element-binding proteins induce an entire pathway of cholesterol synthesis. Biochem Biophys Res Comm 286, 176-183.

20. Vallett SM, Sanchez HB, Rosenfeld JM \& Osborne TF (1996) A direct role of sterol regulatory element binding protein in activation of 3-hydroxy-3-methylglutaryl coenzyme A reductase gene. J Biol Chem 271, 12247-12253. 
21. Horton JD, Bashmakov Y, Shimomura I \& Shimano H (1998) Regulation of sterol regulatory element binding proteins in livers of fasted and refed mice. Proc Natl Acad Sci USA 95, 5987-5992.

22. Horton JD, Goldstein JL \& Brown MS (2002) SREBPs: activators of the complete program of cholesterol and fatty acid synthesis in the liver. $J$ Clin Invest 109, 1125-1131.

23. Shimano H, Yahagi N, Amemiya-Kudo M, Hastry AH, Osuga J, Tamura Y, Shionoiri F, Iizuka Y, Ohashi K, Harada K, Gotoda T, Ishibashi S \& Yamada N (1999) Sterol regulatory element-binding protein-1 as a key transcription factor for nutritional induction of lipogenic enzyme genes. J Biol Chem 274, 35832-35839.

24. Shimomura I, Bashmakov Y, Ikemoto S, Horton JD, Brown MS \& Goldstein JL (1999) Insulin selectively increases SREBP-1c mRNA in the livers of rats with streptozotocin-induced diabetes. Mol Cell Biol 19, 3760-3768.

25. Mead JR, Irvine SA \& Ramji DP (2002) Lipoprotein lipase: structure, function, regulation, and role in disease. $\mathrm{J} \mathrm{Mol} \mathrm{Med}$ 80, 753-769.

26. Santamarina-Fojo S, Gonalez-Navarro H, Freeman L, Wagner E \& Nong Z (2004) Hepatic lipase, lipoprotein metabolism, and atherogenesis. Arterioscler Thromb Vasc Biol 24, 1750-1754.

27. Reeves PG, Nielsen FH \& Fahey GC Jr (1993) AIN-93 purified diets for laboratory rodents: final report of the American Institute of Nutrition ad hoc writing committee on the reformulation of the AIN-76A rodent diet. J Nutr 123, 1939-1951.

28. Naumann C \& Basler R (1993) Methodenbuch Band III. Die Chemische Untersuchung von Futtermitteln (Method Book Volume III. The Chemical Investigation of Feeds). Darmstadt, Germany: VDLUFA-Verlag.

29. Sung JH, Choi SJ, Lee SW, Park KH \& Moon TW (2004) Isoflavones found in Korean soybean paste as 3-hydroxy-3-methylglutaryl coenzyme A reductase inhibitors. Biosci Biotechnol Biochem 68, 1051-1058.

30. Bassler R \& Buchholz H (1993) Methodenbuch Band III. Die Chemische Untersuchung von Futtermitteln (Method Book Volume III. The Chemical Investigation of Feeds). Darmstadt, Germany: VDLUFA-Verlag.

31. Fatufe AA, Hirche F \& Rodehutscord M (2005) Estimates of individual factors of the tryptophan requirement based on protein and tryptophan accretion responses to increasing tryptophan supply in broiler chickens 8-21 days of age. Arch Anim Nutr 59, $181-190$

32. Havel RJ, Eder H \& Bragdon JH (1955) The distribution and chemical composition of ultracentrifugally separated lipoproteins in human serum. $J$ Clin Invest 34, 1345-1353.

33. Terpstra AHM, Van Tintelen G \& West CE (1982) The hypocholesterolemic effect of dietary soy protein in rats. $J$ Nutr 112, 810-817.

34. Hara A \& Radin NS (1978) Lipid extraction of tissues with a low toxicity solvent. Anal Biochem 90, 420-426.

35. De Hoff JL, Davidson JH \& Kritchevsky D (1978) An enzymatic assay for determining free and total cholesterol in tissues. Clin Chem 24, 433-435.

36. Tachibana N, Matsomoto I, Fukui K, Arai S, Kato H, Abe K \& Takematsu K (2005) Intake of soy protein isolate alters hepatic gene expression in rats. J Agric Food Chem 53, 4253-4257.

37. Nagasawa A, Fukui K, Kojima M, et al. (2003) Divergent effects of soy protein diet on the expression of adipocytokines. Biochem Biophys Res Commun 311, 909-914.

38. Goldberg IJ (1996) Lipoprotein lipase and lipolysis: central roles in lipoprotein metabolism and atherogenesis. J Lipid Res 37, 693-707.
39. Krapp A, Ahle S, Kersting S, Hua Y, Kneser K, Nielsen M, Gliemann J \& Beisiegel U (1996) Hepatic lipase mediates the uptake of chylomicrons and $\beta$-VLDL into cells via the LDL receptor-related protein (LRP). J Lipid Res 37, 926-936.

40. Diard P, Malewiak MI, Lagrange D \& Griglio S (1994) Hepatic lipase may act as a ligand in the uptake of artificial chylomicron remnant-like particles by isolated rat hepatocytes. Biochem $J$ 299, 889-894.

41. Marques-Vidal P, Azema C, Collet X, Vieu C, Chap H \& Perret B (1994) Hepatic lipase promotes the uptake of HDL esterified cholesterol by the perfused rat liver: a study using reconstituted HDL particles of defined phospholipids composition. J Lipid Res 35, 373-384.

42. Merkel A \& Heeren J (2005) Give me A5 for lipoprotein hydrolysis!. J Clin Invest 115, 2694-2696.

43. Fruchart-Najib J, Bauge E, Niculescu LS, Phan T, Thomas B, Rommens C, Majd Z, Brewer B, Pennachhio LA \& Fruchart JC (2004) Mechanism of triglyceride lowering in mice expressing human apolipoprotein A5. Biochem Biophys Res Commun 319, 397-404.

44. Schaap FG, Rensen PC, Voshol PJ, Vrings C, van der Vliet HN, Chamuleau RA, Havekes LM, Groen AK \& van Dijk KW (2004) ApoAV reduces plasma triglycerides by inhibiting very low density lipoprotein-triglyceride (VLDL-TG) production and stimulating lipoprotein lipase-mediated VLDL-TG hydrolysis. J Biol Chem 279, 27941-27947.

45. Merkel M, Loeffler B, Kluger M, Fabig N, Geppert G, Pennacchio LA, Laatsch A \& Heeren J (2005) Apolipoprotein AV accelerates plasma hydrolysis of triglyceride-rich lipoproteins by interaction with proteoglycan-bound lipoprotein lipase. J Biol Chem 280, 21553-21560.

46. Jakel H, Nowak M, Moitrot E, Dehondt H, Hum DW, Pennacchio LA, Fruchart-Najib J \& Frucart JC (2004) The liver X receptor ligand T0901317 down-regulates APOA5 gene expression through activation of SREBP-1c. J Biol Chem 279, 45462-45469.

47. Prieur X, Coste H \& Rodriguez JC (2003) The human apolipoprotein $\mathrm{AV}$ gene is regulated by peroxisome proliferator-activated receptor- $\alpha$ and contains a novel farnesoid X-activated receptor response element. J Biol Chem 278, 25468-25480.

48. Vu-Dac N, Gervois P, Jakel H, et al. (2003) Apolipoprotein A5, a crucial determinant of plasma triglyceride levels, is highly responsive to peroxisome proliferators-activated receptor $\alpha$ activators. J Biol Chem 278, 17982-17985.

49. Lasser NL, Roheim PS, Edelstein D \& Eder HA (1973) Serum lipoproteins of normal and cholesterol-fed rats. J Lipid Res 14, $1-8$.

50. Meddings J, Spady D \& Dietschy J (1986) Kinetic constants for receptor-dependent and receptor-independent low density lipoprotein transport in the tissues of the rat and hamster. $J$ Clin Invest 77, 1474-1481.

51. Chiang JY, Kimmel R \& Stroup D (2001) Regulation of cholesterol $7 \alpha$-hydroxylase gene (CYP7A1) transcription by the liver orphan receptor (LXR $\alpha)$. Gene 262, 257-265.

52. Crespo JF, Rodriguez J, Vives R, James JM, Reano M, Daroca P, Burbano C \& Muzquiz M (2001) Occupational IgE-mediated allergy after exposure to lupine seed flour. J Allergy Clin Immunol 108, 295-297.

53. Magni C, Herndl A, Sironi E, Scarafoni A, Ballabio C, Restani P, Bernardini R, Novembre E, Vierucci A \& Duranti M (2005) One- and two-dimensional electrophoretic identification of IgEbinding polypeptides of Lupinus albus and other legume seeds. J Agric Food Chem 53, 4567-4571. 